\title{
Sensitive Detection of Hazardous Explosives via Highly Fluorescent Crystalline Porous Aromatic Frameworks
}

\author{
Ye Yuan, ${ }^{\text {a Hao Ren, }}{ }^{\mathrm{a}}$ Fuxing Sun, ${ }^{\text {a }}$ Xiaofei Jing, ${ }^{\mathrm{a}}$ Kun Cai, ${ }^{\mathrm{a}}$ Xiaojun Zhao, ${ }^{\mathrm{a}}$ Yue Wang, ${ }^{\mathrm{b}}$ Yen Wei ${ }^{\mathrm{c}}$ and \\ Guangshan Zhu ${ }^{* a}$
}

\author{
Received (in $X X X, X X X) X$ th $X X X X X X X X X 20 X X$, Accepted Xth $X X X X X X X X X 20 X X$ \\ DOI: 10.1039/b000000x
}

\begin{abstract}
A three-dimensional (3D) porous aromatic frameworks (PAF-14) with high fluorescence quantum yield was synthesized through synthesizing the luminescent monomer of tetra(4dihydroxyborylphenyl)germanium (TBPGe) as the building blocks. The powder X-ray diffraction (PXRD) analysis of the experimental and simulated patterns display the high crystallinity of PAF-14 with ctn topology. The Argon sorption measurement indicates that PAF-14 possesses high surface area (Brunauer Emmet Teller surface area: $1288 \mathrm{~m}^{2} \mathrm{~g}^{-1}$ ). Significantly, the introduction of germanium into PAF-14 skeletons may bring about a low-lying Lowest Unoccupied Molecular Orbital (LUMO) and the crystalline polymeric backbones enhance the sensitivity of electron delocalization. Therefore the designed PAF-14 is exhibiting high fluorescence quenching ability for hazardous explosives, such as nitrobenzene, 2,4-DNT (2,4-dinitrotoluene) and TNT (2,4,6-trinitrotoluene).
\end{abstract}

\section{Introduction}

Porous materials have experienced rapid progress in the past few decades and have been widely explored for various applications, particularly in gas storage, separation and catalysis. ${ }^{1}$ Besides the well-investigated inorganic porous materials ${ }^{2}$ and hybrid metalorganic frameworks, ${ }^{3}$ porous organic frameworks $(\mathrm{POFs})^{4,5}$ recently emerged as a new class of porous materials attracting escalating interests. A number of different types of POFs, such as covalent organic frameworks (COFs), ${ }^{6-15}$ conjugated microporous polymers (CMPs), ${ }^{16-21}$ polymers of intrinsic microporsity (PIMs), ${ }^{22-25}$ element organic frameworks (EOFs), ${ }^{26-27}$ triazinebased organic frameworks (CTFs), ${ }^{28-31}$ benzimidazole-linked polymers (BILP) ${ }^{32}$, Porous Polymer Networks (PPN) ${ }^{33}$, covalent organic polymers $(\mathrm{COP})^{34}$ and porous aromatic frameworks (PAFs), ${ }^{35-40}$ have been reported. Owing to the robust covalent bonds, high stability and adjustable pore sizes, POFs afford themselves as novel functional materials with great potential for different applications. One possibility is the detection of explosive molecules, which is very important in tackling national security and environmental pollution. ${ }^{41-43}$ As current detection of explosives exclusively relies on the instruments that are either quite expensive or difficult to operate..$^{41}$ Fluorescence quenching used for sensing is a much simpler yet very sensitive technique, which has been investigated in the field of fluorescent MOFs. ${ }^{45-47}$

It is well-known that commercial explosives, such as 2,4-DNT and TNT, possess electronegative group of $-\mathrm{NO}_{2}$. It is expected that electron donating POFs could attract the electronegative $\mathrm{NO}_{2}$ group through coulombic interactions and the crystalline polymeric skeletons of POFs may facilitate efficient exciton migration to enhance quenching sensitivity. ${ }^{48}$ All these features should make POFs promising candidates for the detection of the hazardous explosives. However, this possibility has rarely been explored due to the difficulty to achieve high fluorescence quantum yield in crystalline POFs materials for quenching.

On the basis of our previous success of designing highly porous PAFs, ${ }^{37,40}$ we selected the luminescent monomer, ${ }^{49,50}$ tetra(4-dihydroxyborylphenyl)germanium, as the building block to construct the highly fluorescent PAF-14 (Fig. 1). Introduction of germanium into the PAFs skeletons may bring about a low reduction potential and low-lying LUMO, due to $\sigma^{*}-\pi^{*}$ conjugation arising from the interaction between $\sigma^{*}$ orbital of germanium and $\pi^{*}$ orbital of phenyl rings. ${ }^{51,52}$ Electron delocalization in the crystalline polymeric backbones provides one means of amplification, because interaction of an analyte molecule at any position might quench an excited state or exciton delocalized along the frameworks. ${ }^{53}$ 


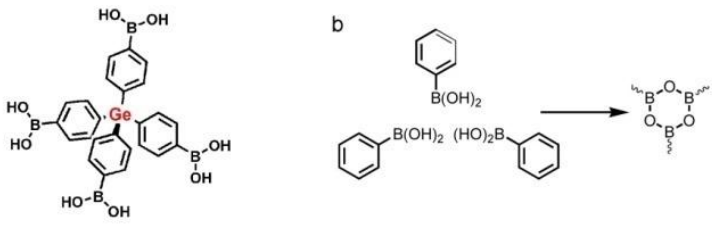

c

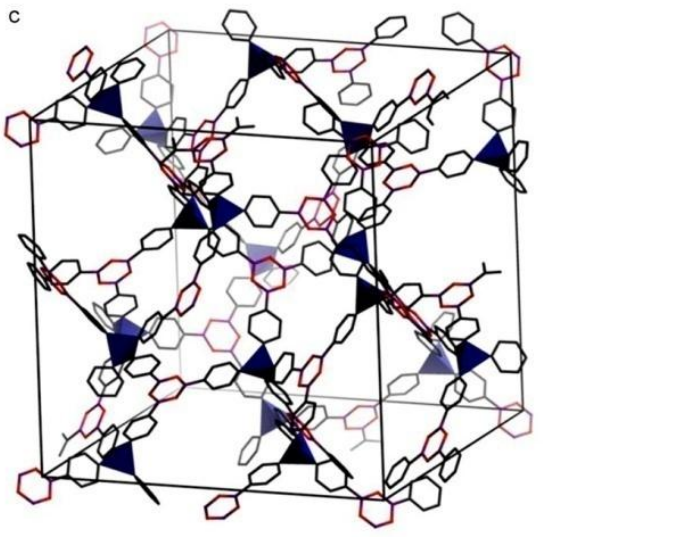

Fig. 1 TBPGe was chosen as the building unit (a). Condensation reaction of boronic acids afforded PAF-14 (b), with model structure of crystalline products PAF-14 (c)

\section{Experimental}

\section{Materials.}

All starting materials were purchased from commercial suppliers and used without further purification unless otherwise noted. tetra(4-dihydroxyborylphenyl)germanium was prepared according to the previously reported method. All reactions were performed under a purified nitrogen atmosphere.

\section{Synthesis of PAF-14.}

Tetra(4-(dihydroxy)borylphenyl)germanium $\quad(56.1 \quad \mathrm{mg}, \quad 0.10$ $\mathrm{mmol}$ ) and $1.0 \mathrm{~mL}$ of a $1: 1 \mathrm{v}: \mathrm{v}$ solution of mesitylene/dioxane was mixed in a pyrex tube. Then the tube was flash frozen at 77 $\mathrm{K}$ (Liquid $\mathrm{N}_{2}$ bath), evacuated to an internal pressure of 150 mTorr and flame sealed. The reaction mixture was heated at $85^{\circ} \mathrm{C}$ for $72 \mathrm{~h}$ to afford a white precipitate which was isolated by filtration over a medium glass frit and washed with anhydrous tetrahydrofuran $(10 \mathrm{~mL})$. The product was immersed in anhydrous tetrahydrofuran $(10 \mathrm{~mL})$ for $4 \mathrm{~h}$, during which the activation solvent was decanted and freshly replenished four times. The solvent was removed under vacuum at room temperature to afford PAF-14 as a white powder (29.1 mg, $65 \%$ ).

\section{Physical measurements.}

TG analysis was performed using a Netzch Sta 449c thermal analyzer system at the heating rate of $10{ }^{\circ} \mathrm{C} \mathrm{min}^{-1}$ in air atmosphere. Fourier Transform Infrared Spectroscopy (FTIR) spectra (film) was measured using a Nicolet Impact 410 Fourier transform infrared spectrometer. The Ar adsorption isotherm was measured on a Quantachrome Autosorb-iQ. PXRD was performed by a Riguku D/MAX2550 diffractometer using $\mathrm{CuK} \alpha$ radiation, $40 \mathrm{kV}, 200 \mathrm{~mA}$ with scanning rate of $0.3 \% \mathrm{~min}(2 \theta)$. SEM and energy-dispersive X-ray spectroscopy (EDS) analyses were performed on a JEOS JSM 6700 . The solid-state ${ }^{13} \mathrm{C}$ and ${ }^{11} \mathrm{~B}$ cross polarization magic angle spinning nuclear magnetic resonance (CP MAS NMR) spectra were recorded on a Bruker AVANCE III $400 \mathrm{WB}$ spectrometer. The absolute quantum yield of fluorescence $\left(\Phi_{\mathrm{FL}}\right)$ was recorded on a Edinburgh FLSP920.

\section{Results and discussion}

Fourier Transform Infrared Spectroscopy (FTIR) and cross polarization magic angle spinning nuclear magnetic resonance (CP MAS NMR) were employed to confirm the bonding and structural features in polymeric materials. The condensation reaction for PAF-14 can be evaluated by FTIR spectra. The appearance of the expected $\mathrm{B}_{3} \mathrm{O}_{3}$ boroxine $\left[\mathrm{B}_{3} \mathrm{O}_{3}\left(707 \mathrm{~cm}^{-1}\right)\right]$ (Fig. 2 ), confirmed the almost completeness of the cross-coupling reaction. The structural assignments of PAF-14 was revealed by CP MAS NMR spectroscopic studies. The solid-state ${ }^{11} \mathrm{~B} \mathrm{CP}$ MAS NMR spectra of the activated product is highly sensitive to the immediate bonding environment of boron. In addition, ${ }^{13} \mathrm{C}$ solid-state NMR experiment was also performed to reveal the local structures of PAF-14, which strongly indicate the environments of respective atoms. As shown in Fig. 3, all the expected signals are matched with the predicted chemical shift values.

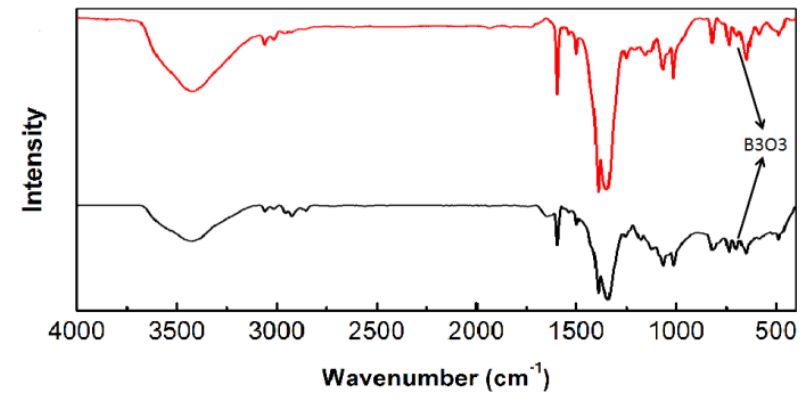

Fig. 2 FT-IR spectrum of PAF-14 (red) and TBPGe (black).
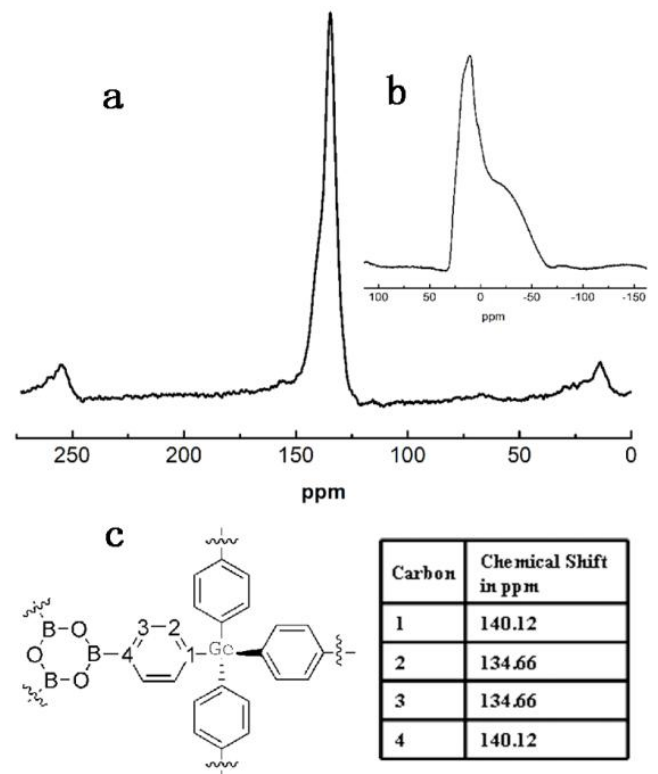

Fig. 3 Solid-state ${ }^{13} \mathrm{C}$ and ${ }^{11} \mathrm{~B}$ NMR spectras for PAF-14 (a and $b$ ).

The experimentally PXRD pattern displays narrow line widths, indicative of the high crystallinity of PAF-14 (Fig. 4). According to the criteria by O'Keeffe, fitting tetrahedral and triangular building units can expediently generate ctn or bor nets. ${ }^{54}$ The consistence between the experimental PXRD pattern and 
simulated ones based on the ctn topology validates the structural models for PAF-14. The optimal simulation reveals the space group of $I-43 \mathrm{~d}$ with the cell parameters of a $=28.69 \AA$. The topology of PAF-14 is the same as that of COF-102 and COF$105 .^{6}$

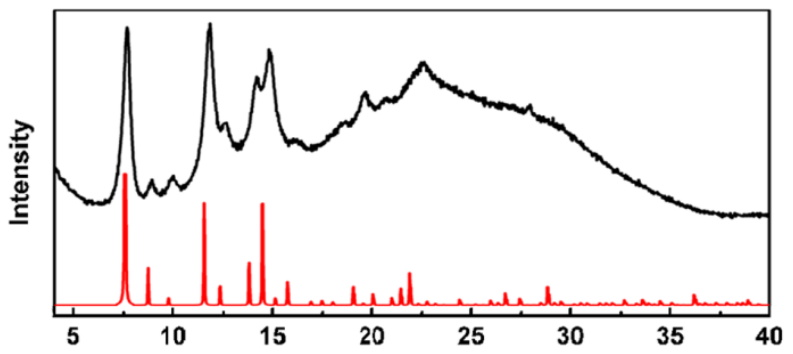

Fig. 4 PXRD profiles for PAF-14 including patterns calculated with the use of Material Studio 5.0, with observed profiles in black, calculated patterns in red.

Scanning electron microscopy (SEM) was performed to probe the shape of PAF-14. As shown in Fig. S2a, PAF-14 is agglomerated nanoparticles with size around $100 \mathrm{~nm}$. In addition, energy-dispersive X-ray spectroscopy (EDS) analysis of the various elements confirmed the compositions of PAF-14 derived from modelled structure (Fig. S2b) and the result was corresponded to formulations predicted from modeling. The thermal stability of PAF-14 was assessed by thermogravimetric analysis (TGA), which reveals it can stabilize up to $230{ }^{\circ} \mathrm{C}$ (Fig. S3).

To characterize the nature of the pores, a fresh PAF-14 sample was fully activated at $100{ }^{\circ} \mathrm{C}$ under dynamic vacuum for $24 \mathrm{~h}$ to remove the guest solvent molecules, and Argon sorption of PAF$14(110 \mathrm{mg})$ was measured at $87 \mathrm{~K}$ from 0 to 760 torr. It exhibits a typical type I isotherm featured by a sharp uptake at the lowpressure region between $\mathrm{P} / \mathrm{P}_{0}=1 \times 10^{-5}$ to $1 \times 10^{-2}$, where $\mathrm{P}$ is gas pressure and $\mathrm{P}_{0}$ is saturation pressure (Fig. 5). The apparent surface area is $1288 \mathrm{~m}^{2} \mathrm{~g}^{-1}$ from BET model and the apparent surface area calculated from Langmuir model is $1345 \mathrm{~m}^{2} \mathrm{~g}^{-1}$. The pore size distribution (PSD) obtained from non-local density functional theory (NLDFT) gave a narrow distribution in microporous region.

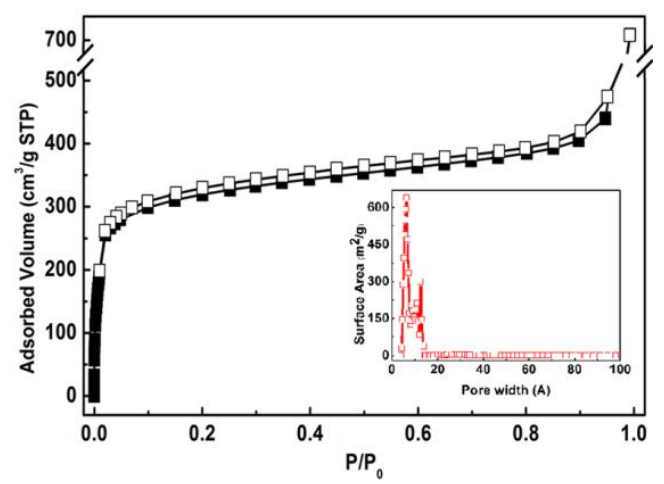

Fig. 5 Reversible argon gas adsorption isotherms for PAF-14 measured at 87 K. STP, standard temperature and pressure. Pore size distribution for PAF-14 (insert) calculated by NLDFT method.

The absolute quantum yield of fluorescence $\left(\Phi_{\mathrm{FL}}\right)$ value of PAF-14 was as high as $37.53 \%$ in $\mathrm{CH}_{2} \mathrm{Cl}_{2}$ at $25{ }^{\circ} \mathrm{C}$ was evaluated using the integrating sphere method. ${ }^{55}$ The delocalized $\pi$ electrons in the systems increased the electrostatic interaction between PAF-14 and analytes. The photoluminescence (PL) spectra of PAF-14 uniformly dispersed in $\mathrm{CHCl}_{3}$ showed maximum emission at $371 \mathrm{~nm}$ (excited at $250 \mathrm{~nm}$ ). As expected, the addition of $150 \mathrm{ppm}$ common aromatic compounds such as benzene, toluene, chlorobenzene, bromobenzene, phenol and aniline basically does not affect the luminescence intensity (Fig. 6). However, quenching effect with different levels could be observed upon the addition of nitroaromatics such as nitrobenzene, 2,4-DNT (2,4-dinitrotoluene) and TNT (2,4,6trinitrotoluene) when dispersed PAF-14 in $\mathrm{CHCl}_{3}$.

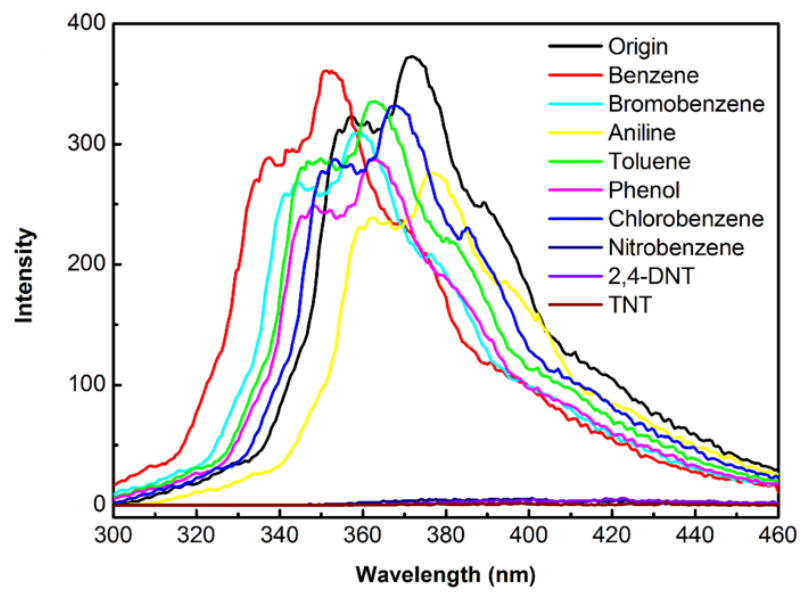

Fig. 6 PL spectra of the $\mathrm{CHCl}_{3}$ solutions of PAF-14 with different analytes (excited at $250 \mathrm{~nm}$ ). Benzene, toluene, chlorobenzene, bromobenzene, phenol, aniline, nitrobenzene, 2,4-DNT, and TNT are represented as red, green, blue, cyan, magenta, yellow, navy, purple and wine, respectively.

As shown in Fig. 7, after the addition of nitrobenzene, 2,4DNT and TNT with different concentrations in the samples respectively, high luminescence quenching ability can be observe for PAF-14, which is much more significant than the MOF-1 $1^{56}$ and $\mathrm{Zn}(\mathrm{II})-\mathrm{MOF}^{57}$. The strong quenching might be explained by the interaction between the host and guest interaction that the great amount of electron donor conjugated groups with delocalized $\pi$ electrons facilitate the electrostatic interaction between PAF-14 and electron deficient compounds. ${ }^{58,59}$ It is worth noting that detection limit among the best for porous materials-based sensors, high-light its potential as a new type of sensor materials. $^{60}$ 

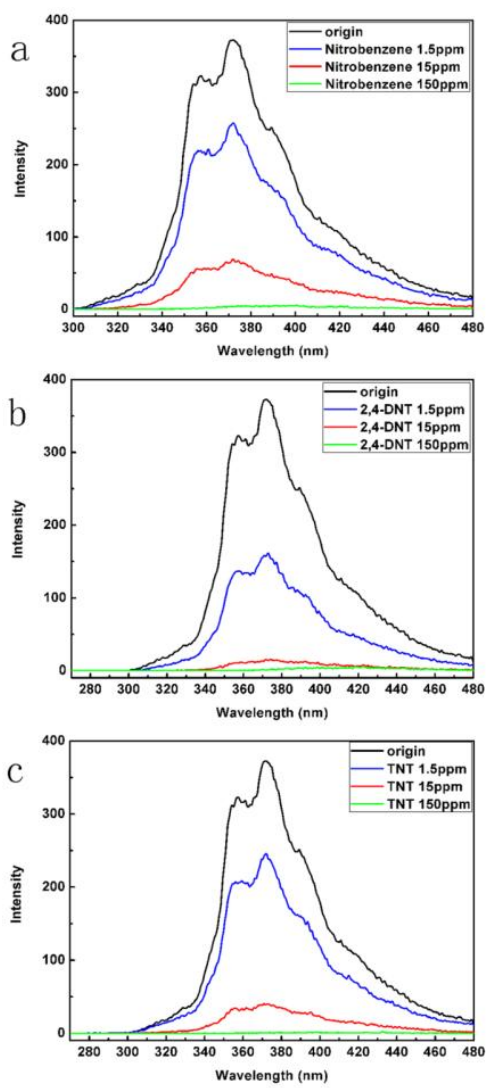

Fig. 7 PL spectra of the $\mathrm{CHCl}_{3}$ solutions of PAF-14 (a, b and c) with different analytes concentration (excited at $250 \mathrm{~nm}$ ).

\section{Conclusions}

In summary, we have selected the luminescent monomer, tetra(4-dihydroxyborylphenyl)germanium (TBPGe), as the building block to construct new PAFs. The three-dimensional (3D) crystalline PAFs material, PAF-14, was successfully designed and synthesized with high fluorescence quantum yield. Experimental results indicate that PAF-14 is highly crystalline with ctn topology. Particularly, owing to the introduction of germanium into the crystalline skeletons, PAF-14 exhibits high luminescence quenching ability for nitroaromatics compounds, making this PAF materials promising for the detection of hazardous explosive compounds.

\section{Acknowledgements}

We are grateful for the financial support of National Basic Research Program of China (973 Program, grant nos. 2012CB821700), Major International (Regional) Joint Research Project of NSFC (grant nos.21120102034) and NSFC (grant nos. 20831002).

\section{Notes and references}

${ }^{a}$ State Key Laboratory of Inorganic Synthesis and Preparative Chemistry, College of Chemistry, Jilin University, Changchun, China (130012), Fax: 860431 85168331; Tel: 860431 85168887; E-mail: zhugs@jlu.edu.cn.

${ }^{b}$ State Key Laboratory of Supramolecular Structure and Materials, College of Chemistry, Jilin University, Changchun, China (130012)

${ }^{C}$.Department of Chemistry, Tsinghua University, Beijing, China (100084) $\dagger$ Electronic Supplementary Information (ESI) available: Details of the study and characterization data are provided.

See DOI: $10.1039 / \mathrm{b} 000000 \mathrm{x}$

1. M. E. Davis, Nature, 2002, 417, 813-821.

2. C. S. Cundy, P. A. Cox, Micropor. Mesopor. Mat., 2005, 82, 1.

3. N. Brun, S. Ungureanu, H. Deleuze, R. Backov, Chem. Soc. Rev., 2011, 40, 771 .

4. A. Thomas, P. Kuhn, J. Weber, M. M. Titirici, M. Antonietti, Macromol Rapid Comm., 2009, 30, 221.

5. N. B. McKeown, P. M. Budd, Macromolecules, 2010, 43, 5163.

6. H. M. El-Kaderi, J. R. Hunt, J. L. Mendoza-Cortes, A. P. Cote, R. E. Taylor, M. O'Keeffe, O. M. Yaghi, Science, 2007, 316, 268.

7. A. P. Cote, A. I. Benin, N. W. Ockwig, M. O'Keeffe, A. J. Matzger, O. M. Yaghi, Science, 2005, 310, 1166.

8. H. Furukawa, O. M. Yaghi, J. Am. Chem. Soc., 2009, 131, 8875.

9. A. P. Cote, H. M. El-Kaderi, H. Furukawa, J. R. Hunt, O. M. Yaghi, J. Am. Chem. Soc., 2007, 129, 12914.

10. X. S. Ding, J. Guo, X. A. Feng, Y. Honsho, J. D. Guo, S. Seki, P. Maitarad, A. Saeki, S. Nagase, D. L. Jiang, Angew. Chem. Int. Edit., 2011, $50,1289$.

11. S. Wan, J. Guo, J. Kim, H. Ihee, D. L. Jiang, Angew. Chem. Int. Edit., 2008, 47, 8826 .

12. S. Wan, J. Guo, J. Kim, H. Ihee, D. L. Jiang, Angew. Chem. Int. Edit., 2009, 48, 5439.

13. L. Chen, Y. Honsho, S. Seki, D. L. Jiang, J. Am. Chem. Soc., 2010, 132,6742 .

14. R. W. Tilford, S. J. Mugavero, P. J. Pellechia, J. J. Lavigne, Adv. Mater., 2008, 20, 2741.

15. R. W. Tilford, W. R. Gemmill, H. C. zur Loye, J. J. Lavigne, Chem. Mater., 2006, 18, 5296-5301.

16. J. X. Jiang, F. Su, A. Trewin, C. D. Wood, N. L. Campbell, H. Niu, C. Dickinson, A. Y. Ganin, M. J. Rosseinsky, Y. Z. Khimyak, A. I. Cooper, Angew. Chem. Int. Edit., 2007, 46, 8574.

17. J. X. Jiang, F. Su, H. Niu, C. D. Wood, N. L. Campbell, Y. Z. Khimyak, A. I. Cooper, Chem. Commun., 2008, 4, 486.

18. E. Stockel, X. F. Wu, A. Trewin, C. D. Wood, R. Clowes, N. L. Campbell, J. T. A. Jones, Y. Z. Khimyak, D. J. Adams, A. I. Cooper, Chem. Commun., 2009, 2, 212.

19. C. D. Wood, B. Tan, A. Trewin, H. J. Niu, D. Bradshaw, M. J. Rosseinsky, Y. Z. Khimyak, N. L. Campbell, R. Kirk, E. Stockel, A. I. Cooper, Chem. Mater., 2007, 19, 2034.

20. R. Dawson, A. Laybourn, R. Clowes, Y. Z. Khimyak, D. J. Adams, A. I. Cooper, Macromolecules, 2009, 42, 8809.

21. R. Dawson, D. J. Adams, A. I. Cooper, Chem. Sci., 2011, 2, 1173.

22. P. M. Budd, B. S. Ghanem, S. Makhseed, N. B. McKeown, K. J.

Msayib, C. E. Tattershall, Chem. Commun., 2004, 2, 230.

23. P. M. Budd, N. B. McKeown, D. Fritsch, J. Mater. Chem., 2005, 15, 1977.

24. N. B. McKeown, P. M. Budd, Chem. Soc. Rev., 2006, 35, 675.

25. B. S. Ghanem, N. B. McKeown, P. M. Budd, J. D. Selbie, D. Fritsch, Adv. Mater., 2008, 20, 2766.

26. M. Rose, W. Bohlmann, M. Sabo, S. Kaskel, Chem. Commun., 2008 $21,2462$.

27. M. Rose, N. Klein, W. Bohlmann, B. Bohringer, S. Fichtner, S. Kaskel, Soft Matter, 2010, 6, 3918.

28. P. Kuhn, M. Antonietti, A. Thomas, Angew. Chem. Int. Edit., 2008, 47,3450 .

29. J. Weber, M. Antonietti, A. Thomas, Macromolecules, 2008, 41, 2880.

30. J. Weber, A. Thomas, J. Am. Chem. Soc., 2008, 130, 6334.

31. P. Kuhn, A. Thomas, M. Antonietti, Macromolecules, 2009, 42, 319.

32. M. G. Rabbani, T. E. Reich, R. M. Kassab, K. T. Jackson, H. M. ElKaderi, Chem. Commun., 2012, 48, 1141.

33. D. Q. Yuan, W. G. Lu, D. Zhao, H. C. Zhou, Adv. Mater., 2011, 23, 3723.

34. H. A. Patel, F. Karadas, A. Canlier, J. Park, E. Deniz, Y. S. Jung, M. Atilhan, C. T. Yavuz, J. Mater. Chem., 2012, 22, 8431.

35. T. Ben, C. Y. Pei, D. L. Zhang, J. Xu, F. Deng, X. F. Jing, S. L. Qiu, Energ. Environ. Sci., 2011, 4, 3991.

36. H. Ren, T. Ben, E. S. Wang, X. F. Jing, M. Xue, B. B. Liu, Y. Cui, S. L. Qiu, G. S. Zhu, Chem. Commun., 2010, 46, 291. 
37. T. Ben, H. Ren, S. Q. Ma, D. P. Cao, J. H. Lan, X. F. Jing, W. C. Wang, J. Xu, F. Deng, J. M. Simmons, S. L. Qiu, G. S. Zhu, Angew. Chem. Int. Edit., 2009, 48, 9457.

38. H. Ren, T. Ben, F. X. Sun, M. Y. Guo, X. F. Jing, H. P. Ma, K. Cai, S. L. Qiu, G. S. Zhu, J. Mater. Chem., 2011, 21, 10348.

39. Y. Yuan, F. X. Sun, H. Ren, X. F. Jing, W. Wang, H. P. Ma, H. J.

Zhao, G. S. Zhu, J. Mater. Chem., 2011, 21, 13498.

40. H. Y. Zhao, Z. Jin, H. M. Su, X. F. Jing, F. X. Sun, G. S. Zhu, Chem. Commun., 2011, 47, 6389.

41. D. T. McQuade, A. E. Pullen, T. M. Swager, Chem. Rev., 2000, 100, 2537.

42. S. J. Toal, W. C. Trogler, J. Mater. Chem., 2006, 16, 2871.

43. M. E. Germain, M. J. Knapp, Chem. Soc. Rev., 2009, 38, 2543.

44. D. S. Moore, Rev. Sci. Instrum., 2004, 75, 2499.

45. S. Muthu, Z. Ni, J. J. Vittal, Inorg. Chim. Acta., 2005, 358, 595.

46. S. Ghosh, P. S. Mukherjee, Organometallics, 2008, 27, 316.

47. A. Lan, K. Li, H. Wu, D. H. Olson, T. J. Emge, W. Ki, M. C. Hong, J. Li, Angew. Chem., Int. Ed., 2009, 48, 2334.

48. B. Gole, S. Shanmugaraju, A. K. Bar, P. S. Mukherjee, Chem. Commun., 2011, 47, 10046

49. M. Gouterman, P. J. Sayer, Mol. Spectrosc., 1974, 53, 319.

50. Y. Yuan, H. Ren, X. F. Jing, W. Wang, H. P. Ma, H. J. Zhao, F. X. Sun J. Mater. Res., 2012, 27, 1417.

51. Y. Yamaguchi, Synthetic Met., 1996, 82, 149.

52. S. Yamaguchi, K. Tamao, Bull. Chem. Soc. Jpn., 1996, 69, 2327.

53. S. Honglae, J. S. Michael, M. Douglas, C. T. William, J. Am. Chem. Soc., 2003, 125, 3821.

54. O. Delgado-Friedrichs, M. O'Keeffe, O. M. Yaghi, Acta. Crystallogr. A., 2006, 62,350

55. Y. H. Xu, L. Chen, Z. Q. Guo, A. Nagai, D. L. Jiang, J. Am. Chem. Soc., 2011, 133, 17622

56. J. S. Yang, T. M. Swager, J. Am. Chem. Soc., 1998, 120, 11864.

57. H. Xu, F. Liu, Y. J. Cui, B. L. Chen, G. D. Qian, Chem. Commun., 2011, 47, 3153

58. G. V. Zyryanov, M. A. Palacios, P. Anzenbacher, Org. Lett., 2008, 10,3681 .

59. B. Gole, A. K. Bar, P. S. Mukherjee, Chem. Commun., 2011, 47, 12137.

60. Y. H. Lee, H. Liu, J. Y. Lee, S. H. Kim, S. K. Kim, J. L. Sessler, Y. Kim, J. S. Kim, Chem-Eur. J., 2010, 16, 5895. 